This is an author produced version of a paper published in Environmental Chemistry.

This paper has been peer-reviewed but may not include the final publisher proof-corrections or pagination.

Citation for the published paper:

Maja A. Larsson, Ingmar Persson, Carin Sjöstedt \& Jon Petter Gustafsson. (2017) Vanadate complexation to ferrihydrite: X-ray absorption spectroscopy and CD-MUSIC modelling. Environmental Chemistry. Volume: 14, Number: 3, pp 141-150. http://dx.doi.org/10.1071/EN16174 .

Access to the published version may require journal subscription. Published with permission from: CSIRO Publishing.

Standard set statement from the publisher:

The definitive version of this article can be found at: http://www.publish.csiro.au/en/EN16174

Epsilon Open Archive http://epsilon.slu.se 


\section{Vanadate complexation to ferrihydrite: X-ray absorption spectroscopy and CD-MUSIC modelling}

Maja A. Larsson ${ }^{\mathrm{A}}$, Ingmar Persson ${ }^{\mathrm{B}}$, Carin Sjöstedt ${ }^{\mathrm{A}}$ and Jon Petter Gustafsson ${ }^{\mathrm{A}, \mathrm{C}, \mathrm{D}}$

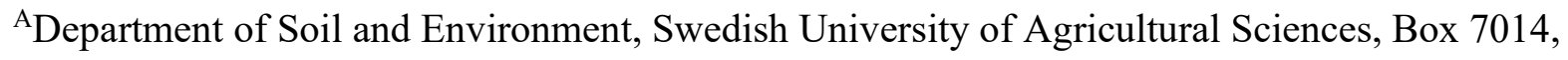
SE-750 07 Uppsala, Sweden

${ }^{\mathrm{B}}$ Department of Molecular Sciences, Swedish University of Agricultural Sciences, Box 7015, SE-750 07 Uppsala, Sweden

${ }^{\mathrm{C}}$ Division of Land and Water Resources Engineering, Royal Institute of Technology, Teknikringen 76, SE-100 44, Stockholm, Sweden

${ }^{\mathrm{D} C}$ Corresponding author. Email: jon-petter.gustafsson@slu.se

Environmental context. Vanadium, a metal pollutant from fossil fuels and slags, may be toxic, thereby necessitating an understanding of its environmental chemistry. One important factor that controls the mobility and bioavailability of vanadium is its binding to iron oxides. This study focuses on the characterization and modelling of vanadium adsorption onto ferrihydrite. The new model can be used to simulate the transport and bioavailability of vanadium in the environment. 


\begin{abstract}
The mobility of vanadium, V, in the environment is influenced by sorption to metal (hydr)oxides, especially those containing iron. The aim with this study is to understand the adsorption behavior of vanadium on poorly ordered (2-line) ferrihydrite (Fh). A further objective was to determine the binding mechanism of vanadate(V) to ferrihydrite surfaces in aqueous suspension to constrain the CD-MUSIC surface complexation model. Vanadium adsorption to ferrihydrite was evaluated by batch experiments which included series with different Fh:V ratios and $\mathrm{pH}$ values. Also, vanadate(V) adsorption was evaluated in presence of phosphate to compete with vanadate $(V)$ for the available surface sites on ferrihydrite. In agreement with earlier studies, vanadate $(\mathrm{V})$ was strongly adsorbed to ferrihydrite and the adsorption increased with decreasing $\mathrm{pH}$. In the presence of phosphate, less vanadate(V) was adsorbed. Analysis by X-ray absorption near-edge structure (XANES) spectroscopy revealed that the adsorbed vanadium was tetrahedral vanadate(V), $\mathrm{VO}_{4}$, regardless of whether vanadate(V) or vanadyl(IV) was added to the system. Spectra collected by extended X-ray absorption fine structure (EXAFS) spectroscopy showed that vanadate $(\mathrm{V})$ is bound primarily as an edge-sharing bidentate complex with $\mathrm{V} \cdots \mathrm{Fe}$ distances around $2.8 \AA$. Based on this information, a surface complexation model was set up in which three bidentate vanadate $(\mathrm{V})$ complexes with different degrees of protonation were included. The model provided a satisfactory description of vanadate(V) adsorption over most of the $\mathrm{pH}$ and concentration ranges studied, also in the presence of competing phosphate ions.
\end{abstract}

\title{
Introduction
}

Vanadium, V, is a redox-sensitive metal that is widely distributed within the Earth's crust. Its main application is within the steel industry in alloys and the major anthropogenic source is from combustion of fossil fuels. Vanadium prevails in the oxidation states $+3,+4$ and +5 in the environment, where the latter two are the most soluble forms. ${ }^{[1]}$ In solution, vanadium(IV) occurs as the oxocation vanadyl, $\mathrm{VO}^{2+}$. Vanadyl is a hard Lewis acid, which can form strong complexes with organic oxygen donor ligands. It is thermodynamically stable at $\mathrm{pH}$ values below $6 .^{[2]}$ Pentavalent vanadium occurs in aerobic conditions under which the dioxovanadium cation $\left(\mathrm{VO}_{2}{ }^{+}\right)$ prevails at low $\mathrm{pH}$, below 3.6, and the anionic form, vanadate (usually occurring as $\mathrm{H}_{2} \mathrm{VO}_{4}{ }^{-}$or $\left.\mathrm{HVO}_{4}{ }^{2-}\right)$ at $\mathrm{pH}$ values above 3.6. Vanadate(V) resembles phosphate and is the most soluble and 
toxic form of vanadium due to its ability to inhibit the function of phosphate-metabolizing enzymes. ${ }^{[3]}$

Vanadium mobility in the environment is to a large extent influenced by sorption to metal (hydr)oxides, especially those containing iron. In Swedish streams, the seasonal fluctuations of the vanadium concentrations follow the same patterns as those of iron. ${ }^{[4]}$ Further, ferric oxyhydroxide has shown to be important for adsorption of dissolved vanadium in waters. ${ }^{[5-8]}$ Studies made on soils have shown a similar pattern where the oxide concentration in the soil plays an important role for vanadium retention. ${ }^{[9-10]}$

The adsorption to metal (hydr)oxides is strongly dependent on the type of (hydr)oxide as well as on solution $\mathrm{pH}$ and on the solid:solution ratio. Vanadium sorption to iron (hydr)oxides is somewhat stronger than for phosphate implying that phosphate is a strong competitor for the binding sites. ${ }^{[9-10]}$ Adsorption to iron (hydr)oxides also takes place at lower $\mathrm{pH}$ values despite electrostatic repulsion of the $\mathrm{VO}^{2+}$ cation. ${ }^{[2,11-12]}$ Goethite is one of the most commonly used iron (hydr)oxide minerals in adsorption studies although there are other (hydr)oxides such as ferrihydrite, which are known to be important for metal retention in the environment. ${ }^{[13]}$ Ferrihydrite is a poorly crystalline iron (hydr)oxide with a large surface area making it an effective adsorbent for oxyanions such as molybdate(VI), tungstate(VI), phosphate and arsenate. ${ }^{[4-15]}$

There have been few attempts to determine vanadium adsorption and complexation to iron (hydr)oxides. X-ray absorption spectroscopic techniques allow for a better insight into mechanisms of complex formation between oxide surfaces and metallates as vanadate(V). Improved knowledge of mechanisms will facilitate development of more accurate adsorption models. Peacock and Sherman ${ }^{[11]}$ reported results from an experiment on vanadium adsorption to goethite $(\alpha-\mathrm{FeOOH})$, studying the vanadate(V) surface complexes formed. They used extended Xray absorption fine structure (EXAFS) spectroscopy to determine the structure of the surface complex and the results showed that vanadate(V) adsorbs as a bidentate corner-sharing innersphere complex to the goethite surface. The same binding mode was suggested for arsenate adsorption to different iron (hydr)oxides including hematite, goethite and ferrihydrite. ${ }^{[16]}$ However, this conclusion was questioned by Loring et al. ${ }^{[17]}$, who proposed monodentate coordination of arsenate(V) on goethite based on a combination of X-ray diffraction (XRD), EXAFS and infrared spectroscopic results. 
The aim with this study is to understand the adsorption of vanadyl(IV) and vanadate(V) to ferrihydrite surfaces in single-sorbate systems as well as in competitive systems with phosphate at varying $\mathrm{pH}$ and solid:solution ratios. A further objective was to determine the geometry of the vanadate(V)-ferrihydrite complex(es) by using data from EXAFS spectroscopy and to optimize surface complexation constants of vanadate(V) to ferrihydrite by using the CD-MUSIC model ${ }^{[18]}$. The idea was to suggest a model that can be a part of an extended model that describes vanadate(V) adsorption in soils.

\section{Experimental}

\section{Batch experiments}

2-line ferrihydrite was prepared using a method adapted from Swedlund and Webster ${ }^{[19]}$ and Schwertmann and Cornell. ${ }^{[20]}$ A solution containing $36 \mathrm{mM} \mathrm{Fe}\left(\mathrm{NO}_{3}\right)_{3}$ and $12 \mathrm{mM} \mathrm{NaNO}$ was brought to $\mathrm{pH} 8.0$ through dropwise addition of $4 \mathrm{M} \mathrm{NaOH}$, which was prepared immediately before use. The resulting suspension was thereafter aged for $18-22 \mathrm{~h}$ at $20^{\circ} \mathrm{C}$. Analysis of the suspension by EXAFS spectroscopy has confirmed the formation of 2-line ferrihydrite. ${ }^{[21]}$ After aging, the suspension was back-titrated with $0.1 \mathrm{M} \mathrm{HNO}_{3}$ to $\mathrm{pH} 4.6$ and stirred for about 15 min before commencing the batch experiments with the purpose to prevent $\mathrm{CO}_{2}$ to enter during the sample preparation.

The batch experiment samples were prepared in $40 \mathrm{~mL}$ acid-washed polypropylene bottles in seven different series (Table S1). The series were prepared at two different laboratories; the R series were processed at KTH Royal Institute of Technology (KTH) in May 2009 and the L series were prepared at the Swedish University of Agricultural Sciences (SLU) in September 2009. Seven of the series were single-sorbate systems with different Fe:V ratios. In an eighth series, a ternary system was prepared by adding both vanadate and phosphate to the ferrihydrite suspension. One single-sorbate system with phosphate and ferrihydrite was also processed (for details see Supporting Information, Section A). In all cases, the ferrihydrite suspension was mixed with a stock solution of $\mathrm{NaNO}_{3}$ to obtain an ionic strength of $0.01 \mathrm{M}$. Stock solutions of vanadate were prepared from solid sodium metavanadate $\left(\mathrm{NaVO}_{3}, 99.9 \%\right.$, Sigma-Aldrich), whereas phosphate solutions were prepared by using sodium dihydrogen phosphate dihydrate $\left(\mathrm{NaH}_{2} \mathrm{PO}_{4} \times 2 \mathrm{H}_{2} \mathrm{O}, 99 \%\right.$, Alfa-Aesar) salt. Use of EXAFS spectroscopy and ion chromatography confirmed that 
metavanadate was converted immediately to dissolved vanadate upon contact with water (data not shown), in agreement with the findings of Crans et al. ${ }^{[22]}$ Different volumes of acid $\left(\mathrm{HNO}_{3}\right)$ or base $(\mathrm{NaOH})$ were added to obtain a range of $\mathrm{pH}$ values within each series. The samples were equilibrated for 45 hours in an end-over-end shaker at room temperature. No special precautions (i.e. use of $\mathrm{N}_{2}$ atmosphere etc.) were made to prevent vanadium redox reactions from taking place in these systems.

After equilibration, the samples were centrifuged for $30 \mathrm{~min}$ at $3000 \mathrm{rpm}$ and filtered through a $0.2 \mu \mathrm{m}$ single-use Acrodisc PF filters (Pall Corp., Port Washington, NY, USA). The pH value was measured on unfiltered samples, using a Radiometer combination electrode (Radiometer Analytical SAS, Lyon, France). The filtered samples were acidified to a final concentration of 1

$\% \mathrm{HNO}_{3}$ (65\% suprapur $\mathrm{HNO}_{3}$, Merck-Millipore), and stored at $8^{\circ} \mathrm{C}$ until analysis for total vanadium and iron with (i) inductively coupled plasma mass spectroscopy (ICP-MS) using a Perkin-Elmer ELAN 6100 instrument (Perkin-Elmer Inc., Waltham, MA, USA; for samples processed at SLU), or with (ii) inductively coupled plasma optical emission spectroscopy (ICPOES) using a Perkin-Elmer Optima 3000 DV instrument (Perkin Elmer Inc. as above; for samples prepared at $\mathrm{KTH}$ ). Dissolved $\mathrm{PO}_{4}-\mathrm{P}$ concentrations were analyzed on filtered samples with the acid molybdate method using flow injection analysis (Aquatec-Tecator Autoanalyzer). At low pH $(<4)$, some samples were relatively high in dissolved $\mathrm{Fe}(>1 \%$ of the initial Fe concentration). This was either due to ferrihydrite dissolution or because of colloidal ferrihydrite passing the filter under these conditions. As both of these processes could affect the sorption of vanadate(V) or phosphate, such samples were not considered in this study.

\section{$X$-ray absorption spectroscopy}

$\mathrm{X}$-ray spectroscopic measurements of ferrihydrite samples treated with vanadium were performed at the vanadium $K$-edge at 5,465 eV. Measurements were conducted at two different synchrotron light sources; the wiggler beam line 4-3 at Stanford Synchrotron Radiation Lightsource (SSRL), Stanford, USA, and the wiggler beam line I811 at the MAX-Lab, Lund, Sweden. The station at SSRL operated at $3.0 \mathrm{GeV}$ with a current of $97-100 \mathrm{~mA}$. Higher-order harmonics were reduced by mirrors and measurements were performed in fluorescence mode using a 13 element Ge array fluorescence detector. At MAX-Lab, the station at operated at $1.5 \mathrm{GeV}$ and a maximum current of $230 \mathrm{~mA}$. Higher-order harmonics were reduced by detuning the second monochromator crystal 
and the scans were collected in fluorescence mode using a Passivated Implanted Planar Silicon (PIPS) detector. Both stations were equipped with a $\mathrm{Si}[111]$ double crystal monochromator and internal energy calibration was made with a metallic vanadium foil assigned to $5,465 \mathrm{eV}$. ${ }^{[23]}$

Table 1. Overview of vanadium samples adsorbed to ferrihydrite and laboratory standards

The samples were analyzed by XANES (X) and/or EXAFS (E) spectroscopy

\begin{tabular}{|c|c|c|c|c|c|c|c|c|}
\hline Sample & Added V & Analysis & Synchrotron & pH & $\begin{array}{c}\mathbf{F e} \\
(\mathbf{m M})\end{array}$ & $\begin{array}{c}\mathrm{V} \\
(\mu \mathrm{M})\end{array}$ & $\begin{array}{c}\mathbf{P} \\
(\mu \mathrm{M})\end{array}$ & $n$ scans \\
\hline \multicolumn{9}{|l|}{ Ferrihydrite } \\
\hline A & $\mathrm{H}_{2} \mathrm{~V}^{\mathrm{V}} \mathrm{O}_{4}^{-}$ & $\mathrm{E}$ & MAX-Lab & 3.6 & 1 & 50 & 0 & 8 \\
\hline B & $\mathrm{H}_{2} \mathrm{~V}^{\mathrm{V}} \mathrm{O}_{4}^{-}$ & $\mathrm{E}$ & MAX-Lab & 3.9 & 1 & 50 & 0 & 8 \\
\hline $\mathrm{C}$ & $\mathrm{V}^{\mathrm{IV}} \mathrm{O}^{2+}$ & $\mathrm{X}$ & SSRL & 4.51 & 3 & 50 & 0 & 2 \\
\hline D & $\mathrm{V}^{\mathrm{IV}} \mathrm{O}^{2+}$ & $X$ & SSRL & 5.70 & 3 & 50 & 0 & 2 \\
\hline $\mathbf{E}$ & $\mathrm{H}_{2} \mathrm{~V}^{\mathrm{V}} \mathrm{O}_{4}^{-}$ & $\mathrm{E}$ & SSRL & 6.23 & 3 & 50 & 600 & 6 \\
\hline $\mathbf{F}$ & $\mathrm{H}_{2} \mathrm{~V}^{\mathrm{V}} \mathrm{O}_{4}^{-}$ & $X \& E$ & SSRL & 6.50 & 3 & 50 & 0 & 6 \\
\hline $\mathbf{G}$ & $\mathrm{H}_{2} \mathrm{~V}^{\mathrm{V}} \mathrm{O}_{4}^{-}$ & $\mathrm{E}$ & SSRL & 9.39 & 3 & 50 & 0 & 6 \\
\hline \multicolumn{9}{|l|}{ Standards } \\
\hline $\mathrm{VO}^{2+}(\mathrm{aq})$ & & $X$ & SSRL & & & & & 2 \\
\hline $\mathrm{V}_{2} \mathrm{O}_{5}(\mathrm{~s})$ & & $\mathrm{X}$ & SSRL & & & & & 2 \\
\hline $\mathrm{H}_{2} \mathrm{VO}_{4}^{-}(\mathrm{aq})$ & & $X$ & SSRL & & & & & 1 \\
\hline $\mathrm{Na}_{3} \mathrm{VO}_{4}(\mathrm{~s})$ & & $\mathrm{E}$ & MAX-Lab & & & & & 8 \\
\hline $\mathrm{H}_{2} \mathrm{VO}_{4}^{-}(\mathrm{aq})$ & & $\mathrm{E}$ & MAX-Lab & & & & & 9 \\
\hline
\end{tabular}

A total of seven ferrihydrite samples treated with aqueous solution of either $\mathrm{NaVO}_{3}$ or $\mathrm{VOSO}_{4}$ (according to the procedure described for batch experiments) were analyzed by XANES and/or EXAFS spectroscopy (Table 1). In addition, vanadium laboratory standards were also analyzed. Two scans per sample were applied to XANES analysis and in those analyses where EXAFS measurements were included, a minimum of six scans were averaged after energy calibration by means of the EXAFSPAK program package. ${ }^{[24]}$ During the data collection, no changes in spectral features were observed that would indicate oxidation or reduction caused by beam damage.

All XANES spectra were treated in the Athena software, version 0.8.061. ${ }^{[25]}$ Sample scans were individually studied to identify and discard poor scans. The scans were then energy calibrated by use of a reference foil and subsequently normalized in the same manner as performed by Wong et al. ${ }^{[26]}$ Fitting of the spectra was performed by using the peak fit function in Athena where the preedge in the vanadium spectrum was fitted to line shapes, which included an arc tangent and an error function together with Gaussian peak shapes. From these shapes, pre-edge characteristics such as area, centroid position and the ratio between height and area of the pre-edge could be calculated. 
The EXAFSPAK program package was used for final data treatment of the EXAFS spectra, including refinement of structure parameters using FEFF-calculated EXAFS parameters. ${ }^{[27]}$ The standard deviations for the refined parameters were obtained from $k^{3}$-weighted least-squares refinements of the EXAFS function $\chi(k)$, and did not include systematic errors of the measurements. These statistical error values allowed reasonable comparisons e.g. of the significance when comparing relative shifts in the distances. However, the variations in the refined parameters, including the shift in the $E_{\mathrm{o}}$ value (for which $k=0$ ), using different models and data ranges, indicated that the absolute accuracy of the distances given for the separate complexes is within \pm 0.005 to $0.02 \AA$ for well-defined interactions. The "standard deviations" given in the text have been increased accordingly to include estimated additional effects of systematic errors.

\section{Surface complexation modelling}

In this work we used the three-plane CD-MUSIC model ${ }^{18}$ with the surface charging parameters of Tiberg et al. ${ }^{[28]}$ The specific surface area was set to $650 \mathrm{~m}^{2} \mathrm{~g}^{-1}$ and the site density to 7.8 sites $\mathrm{nm}^{-}$ 2 . The sites assumed to determine proton charging were represented by singly coordinated $\equiv \mathrm{FeOH}$ groups and triply coordinated $\equiv \mathrm{Fe}_{3} \mathrm{O}$ groups, with 6.25 and 1.55 sites nm$^{-2}$, respectively. Moreover, the model employed relatively high values for the inner-layer and outer-layer capacitances, being 1.15 and $0.9 \mathrm{~F} \mathrm{~m}^{-2}$, respectively, to reflect the spherical particle form of ferrihydrite. ${ }^{[29]}$ In the model, surface complexes with metal ions and anions are assumed to form only with the $\equiv \mathrm{FeOH}$ groups since these are generally considered the most reactive. ${ }^{[30]}$ The model is similar (but not identical) to the recently developed ferrihydrite model of Hiemstra and Zhao ${ }^{[31]}$, which relied on the structural determinations of ferrihydrite by Michel et al. ${ }^{[32-33]}$. Our model is more simplified than Hiemstra and Zhao's model, as we do not consider edge-sharing and corner-sharing sites separately - this brings down the number of species considerably, and the differences obtained with the two model types are very small (data not shown).

The surface complexation reactions with vanadate $(V)$ were constrained from spectroscopic evidence of this study (c.f. Results section). In the case of phosphate adsorption, a model description assuming bidentate complexes to be dominant was used. It included CD values calculated by Hiemstra and van Riemsdijk ${ }^{[34]}$ using DFT (density functional theory). A similar model results if monodentate complexes, involved in weak interaction with a neighboring 
deprotonated surface site, are dominant as suggested by Loring et al. ${ }^{[17]}$ for arsenate(V) adsorption to goethite.

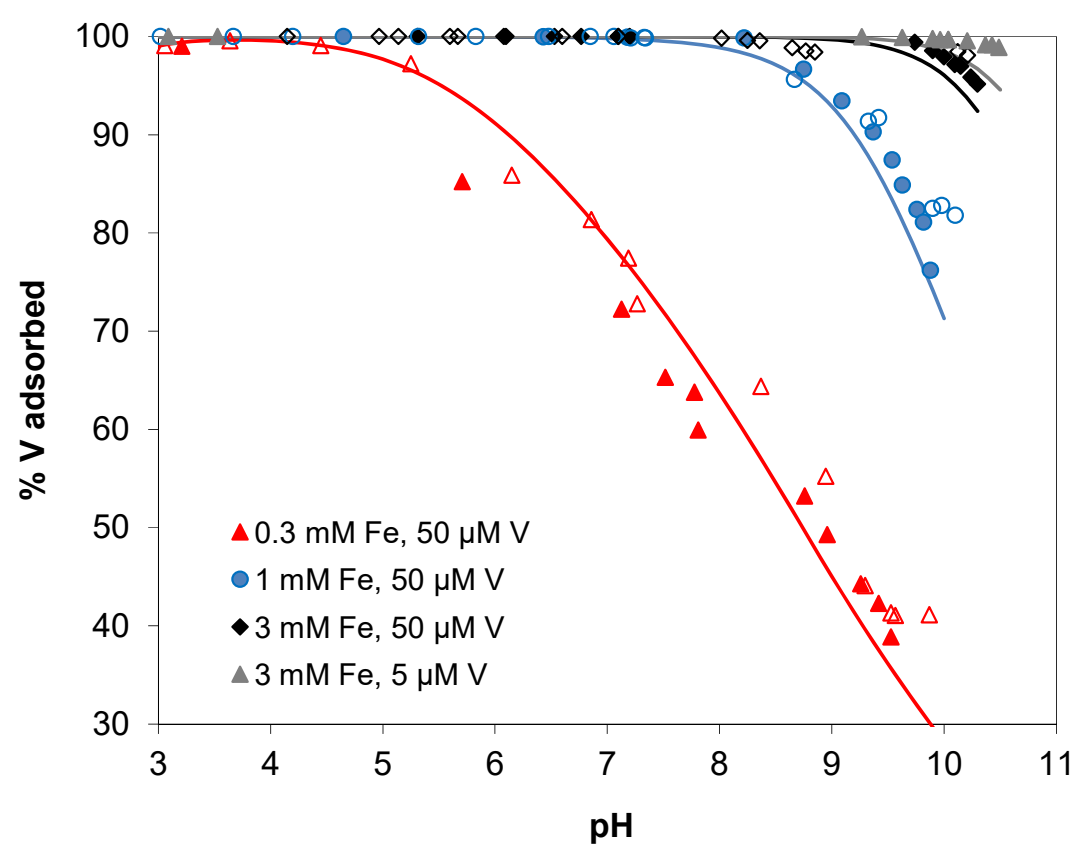

Fig. 1. Adsorption of vanadate(V) in single sorbate systems with different Fe and V concentrations. Points are observations and lines are model fits. The filled and empty symbols denote the $\mathrm{L}$ and $\mathrm{R}$ experimental series, respectively (see text).

Surface complexation constants for vanadate were optimized with PEST ${ }^{[35]}$, which is integrated in Visual MINTEQ. PEST uses a Gauss-Marquardt-Levenberg algorithm for parameter estimation and minimizes the weighted sum of squared differences between modelgenerated observation values and the measured values of percent adsorbed vanadate. Three bidentate complexes were considered (Table 3$)$, two of which $\left(\equiv(\mathrm{FeO})_{2} \mathrm{VO}_{2}{ }^{2-}\right.$ and $\left.\equiv(\mathrm{FeO})_{2} \mathrm{VOOH}^{-}\right)$are similar to complexes used for arsenate and phosphate on ferrihydrite in previous work. ${ }^{[34,36]}$ At low $\mathrm{pH}$, however, a third complex was needed to describe the data, and for this purpose the complex $\equiv(\mathrm{FeO})_{2} \mathrm{~V}(\mathrm{OH})_{2}$ was introduced (c.f. below). Initially both the surface complexation constants and CD values were allowed to fit. However, as it was found that equally good fits could be obtained by a wide range of CD values, the $\Delta z_{0}$ values for the $\equiv(\mathrm{FeO})_{2} \mathrm{VO}_{2}{ }^{2-}$ and $\equiv(\mathrm{FeO})_{2} \mathrm{VOOH}^{-}$complexes were constrained to within 0.1 units of the $\mathrm{CD}$ values for the analogous surface complexes with phosphate (see Table 3), whereas for the 
$\equiv(\mathrm{FeO})_{2} \mathrm{~V}(\mathrm{OH})_{2}$ complex the $\mathrm{CD}$ value was fitted. Moreover, the model optimization was initially carried out for the single-sorbate systems only. However, the CD value and equilibrium constant of the $\equiv(\mathrm{FeO})_{2} \mathrm{~V}(\mathrm{OH})_{2}$ complex were very poorly constrained using this procedure. For this reason also the data series was included in which phosphate was added as a competitive ion.

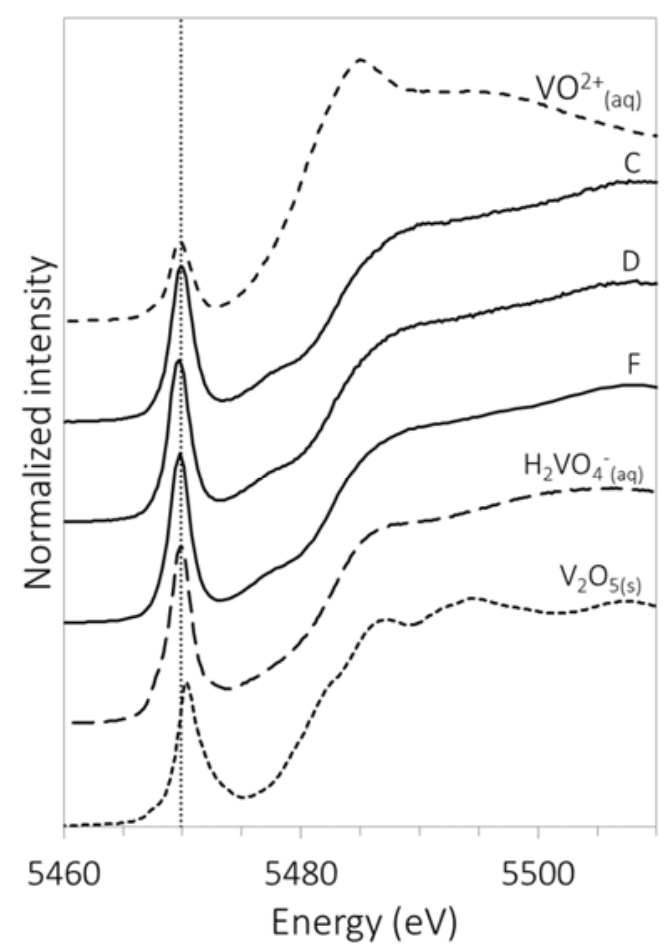

Fig. 2. Stacked, normalized vanadium K-edge XANES spectra of vanadium adsorbed to ferrihydrite (solid lines) and vanadium laboratory standards (dashed lines). The vertical line is positioned at the pre-edge absorption maximum for tetrahedral vanadate at $5469.8 \mathrm{eV}$.

\section{Results}

\section{Vanadium adsorption to ferrihydrite}

Vanadate(V) adsorption to ferrihydrite decreased with increasing $\mathrm{pH}$ (Fig. 1). At the lowest $\mathrm{pH}$, around $\mathrm{pH} 3$, almost $100 \%$ vanadate $(\mathrm{V})$ was sorbed, but the adsorption edge was displaced to lower $\mathrm{pH}$ values when a lower Fe: $\mathrm{V}$ ratio was used. At the highest Fe: $\mathrm{V}$ ratio $(3 \mathrm{mM}$ Fe to $5 \mu \mathrm{M}$ $\mathrm{V})$, the main fraction ( $>98 \%$ ) of the added vanadate $(\mathrm{V})$ was adsorbed to the ferrihydrite over the whole $\mathrm{pH}$ range, from $\mathrm{pH} 3$ to 10.5 . 
Vanadium K-edge XANES spectroscopy was used to evaluate the oxidation state and symmetry of vanadium bound to ferrihydrite (Fig. 2). The area, position and shape of the pre-edge peak in the XANES spectra corresponded well with the intensity and shape of the vanadate(V) solution reference, whereas it differed from both dissolved vanadyl(IV) (i.e. $\mathrm{VO}^{2+}$ ) and solid vanadium pentoxide (i.e. $\mathrm{V}_{2} \mathrm{O}_{5}(\mathrm{~s})$ ) (Table S2). This confirms that the added vanadate remained as tetrahedral vanadium $(\mathrm{V})$ and that it was not reduced or changed in coordination. For systems in which vanadium(IV) was added, the use of XANES spectroscopy revealed that the vanadium had been converted to vanadate(V) at both $\mathrm{pH}$ values examined, $\mathrm{pH} 4.5$ and 5.7 (Fig. 2). The height and shape of the vanadium pre-edge was identical to those of tetrahedral vanadate(V).
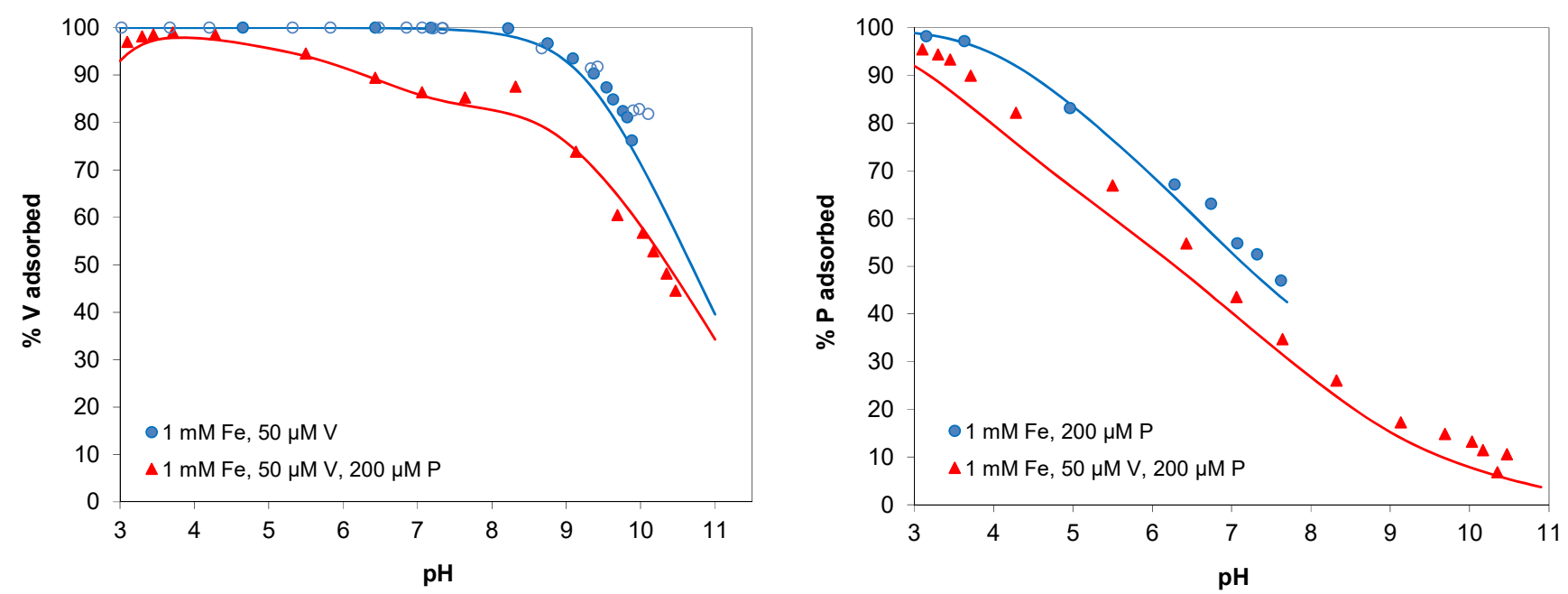

Fig. 3. Left: Adsorption of vanadate to ferrihydrite in in the absence or presence of phosphate. Right: Adsorption of phosphate to ferrihydrite in in the absence or presence of vanadate. Points are observations and lines are model fits. The filled and empty symbols denote the $\mathrm{L}$ and $\mathrm{R}$ experimental series, respectively (see text).

When phosphate was added as a competing anion, less vanadate was adsorbed compared to the single-sorbate system (Fig. 3). A decrease in vanadate sorption due to phosphate competition could be seen at $\mathrm{pH}>4$. The competition with phosphate created a shoulder in the vanadium adsorption edge close to $\mathrm{pH}$ 7.5. This shoulder could not be seen for phosphate which at least in part could be explained by the four-fold higher phosphate additions made to these systems. Still, there was a decrease in phosphate sorption as a result of vanadate competition. 

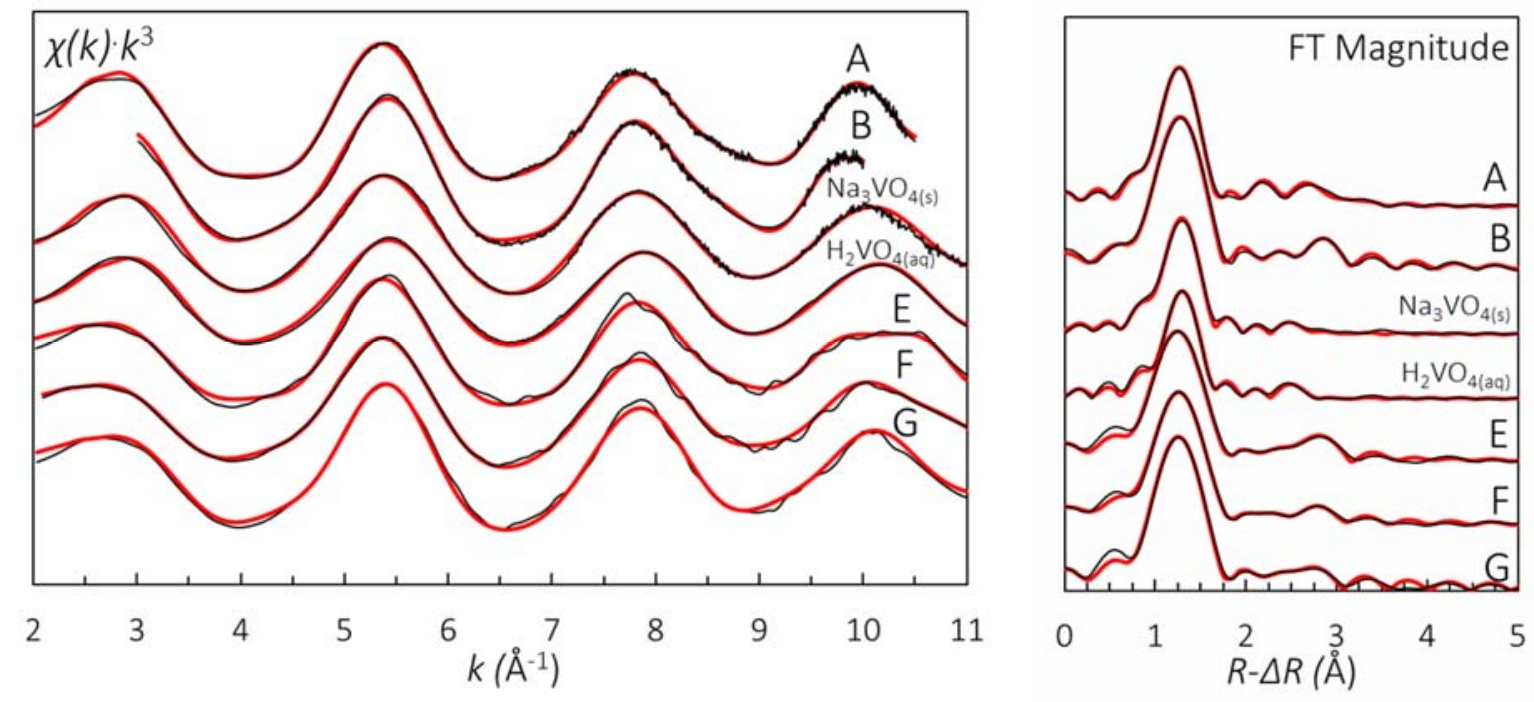

Fig. 4. Left: Stacked $k^{3}$-weighted EXAFS spectra for vanadium sorbed to ferrihydrite at different pH values, see Table 1. Right: Stacked Fourier Transforms (FT magnitudes) of the $k^{3}$-weighted EXAFS spectra. Black and red lines represent experimental data and fits, respectively.

\section{Structure of adsorbed vanadate(V)}

The EXAFS spectra were modelled reasonably well with vanadate(V) bound as an edge-sharing bidentate complex to the ferrihydrite (Fig. 4). A V-O bond distance of $\sim 1.72 \AA$ was used in the model for all four V-O bonds in adsorbed vanadate(V) (Table 2). In addition to the V-O distance, a single $\mathrm{V} \cdots \mathrm{Fe}$ distance was observed at a distance of 2.79 in all samples except for sample $\mathrm{E}$ where it was observed at $2.86 \AA$. Inclusion of three-leg multiple scattering (MS) paths for V-O-O (inner-core tetrahedral $\mathrm{VO}_{4}$ ) significantly improved the model fit. Assuming that the Fe-O bond distance was $2.00 \AA$, the mean distance in octahedral iron(III) complexes with oxygen donor ligands, ${ }^{[37]}$ and that the oxygen singly bound to vanadium also binds to iron(III) in the ferrihydrite surface, the $\mathrm{V}-\mathrm{O}-\mathrm{Fe}$ angle becomes $97-101^{\circ}$. This is a strong indication that iron(III) binds the vanadate( $\mathrm{V})$ ion bidentately forming an edge-sharing, almost square-planar $\mathrm{V}-\mathrm{O}_{2}-\mathrm{Fe}$ surface complex. However, except for sample A, the Debye-Waller factors of the $\mathrm{V} \cdots \mathrm{Fe}$ distance were rather large, which may indicate a heterogeneity in the vanadate(V) binding environment on ferrihydrite. 
Table 2. Summary of refinement of curve-fitting of vanadium EXAFS data

\begin{tabular}{|c|c|c|c|c|c|c|c|}
\hline Sample & Distance & $d / \AA$ & $\sigma^{2} / \AA^{2}$ & $N$ & $\begin{array}{l}\text { k-range } \\
\text { refined }\end{array}$ & $S_{0}^{2}$ & $F$ \\
\hline \multicolumn{8}{|l|}{ Standards } \\
\hline \multirow[t]{2}{*}{$\mathrm{Na}_{3} \mathrm{VO}_{4}(\mathrm{~s})$} & $\mathrm{V}-\mathrm{O}$ & $1.723(1)$ & $0.0043(1)$ & 4 & $2.0-12.0$ & $0.85(1)$ & 9.4 \\
\hline & $\mathrm{MS}\left(\mathrm{VO}_{4}\right)$ & $3.139(4)$ & $0.0053(5)$ & 12 & & & \\
\hline \multirow[t]{2}{*}{$\mathrm{H}_{2} \mathrm{VO}_{4}^{-}(\mathbf{a q})$} & $\mathrm{V}-\mathrm{O}$ & $1.719(1)$ & $0.0033(1)$ & 4 & $2.0-12.0$ & $0.80(1)$ & 9.1 \\
\hline & $\mathrm{MS}\left(\mathrm{VO}_{4}\right)$ & $3.106(2)$ & $0.0049(3)$ & 12 & & & \\
\hline \multicolumn{8}{|c|}{ Ferrihydrite samples } \\
\hline \multirow[t]{4}{*}{ A } & $\mathrm{V}-\mathrm{O}$ & $1.724(1)$ & $0.0058(1)$ & 4 & $3.0-10.5$ & $0.87(1)$ & 8.7 \\
\hline & $\mathrm{V} \cdots \mathrm{Fe}$ & $2.792(3)$ & $0.0078(4)$ & 1 & & & \\
\hline & $\mathrm{MS}\left(\mathrm{VO}_{4}\right)$ & $3.192(2)$ & $0.008(3)$ & 12 & & & \\
\hline & $\angle \mathrm{V}-\mathrm{O}-\mathrm{Fe}:$ & & & & & & \\
\hline \multirow[t]{5}{*}{ B } & $\mathrm{V}-\mathrm{O}$ & $1.715(1)$ & $0.0063(1)$ & 4 & $3.0-10.0$ & $1.02(1)$ & 13.7 \\
\hline & $\mathrm{V} \cdots \mathrm{Fe}$ & $2.787(3)$ & $0.0165(11)$ & 1 & & & \\
\hline & $\mathrm{MS}\left(\mathrm{VO}_{4}\right)$ & $3.159(4)$ & $0.0078(5)$ & 12 & & & \\
\hline & $\mathrm{V}-\mathrm{O}-\mathrm{Fe}$ & $3.254(4)$ & $0.0121(4)$ & 4 & & & \\
\hline & $\angle \mathrm{V}-\mathrm{O}-\mathrm{Fe}:$ & & & & & & \\
\hline \multirow[t]{4}{*}{$\mathbf{E}$} & $\mathrm{V}-\mathrm{O}$ & $1.706(2)$ & $0.0060(2)$ & 4 & $2.0-11.0$ & $0.90(2)$ & 14.1 \\
\hline & $\mathrm{V} \cdots \mathrm{Fe}$ & $2.86(2)$ & $0.018(3)$ & 1 & & & \\
\hline & $\mathrm{MS}\left(\mathrm{VO}_{4}\right)$ & $3.137(9)$ & $0.020(3)$ & 12 & & & \\
\hline & $\angle \mathrm{V}-\mathrm{O}-\mathrm{Fe}:$ & $.7^{\circ}$ & & & & & \\
\hline \multirow[t]{5}{*}{$\mathbf{F}$} & $\mathrm{V}-\mathrm{O}$ & $1.719(2)$ & $0.0054(2)$ & 4 & $2.0-11.0$ & $0.89(2)$ & 13.0 \\
\hline & $\mathrm{V} \cdots \mathrm{Fe}$ & $2.789(10)$ & $0.016(2)$ & 1 & & & \\
\hline & $\mathrm{MS}\left(\mathrm{VO}_{4}\right)$ & $3.15(2)$ & $0.014(3)$ & 12 & & & \\
\hline & $\mathrm{MS}\left(\mathrm{VO}_{4}\right)$ & $3.46(3)$ & $0.010(3)$ & $4+12$ & & & \\
\hline & $\angle \mathrm{V}-\mathrm{O}-\mathrm{Fe}:$ & & & & & & \\
\hline \multirow[t]{4}{*}{$\mathbf{G}$} & $\mathrm{V}-\mathrm{O}$ & $1.720(2)$ & $0.0047(2)$ & 4 & $2.0-11.0$ & $0.91(2)$ & 11.3 \\
\hline & $\mathrm{V} \cdots \mathrm{Fe}$ & $2.789(10)$ & $0.016(2)$ & 1 & & & \\
\hline & $\mathrm{MS}\left(\mathrm{VO}_{4}\right)$ & $3.147(9)$ & $0.020(3)$ & 12 & & & \\
\hline & $\angle \mathrm{V}-\mathrm{O}-\mathrm{Fe}:$ & & & & & & \\
\hline
\end{tabular}

\footnotetext{
Abbreviations: $d=$ Atomic distance; $\sigma^{2}=$ Debye-Waller factor; $\mathrm{N}=$ Coordination number; $\mathrm{S}_{0}{ }^{2}=$ passive amplitude reduction factor; $\mathrm{F}=$ goodness-of-fit parameter. ${ }^{[24]}$
} 
In earlier studies, wavelet transform (WT) analysis has been shown to be a powerful tool to identify heavy backscatterers such as iron. ${ }^{[28,38]}$ In this study, the WT analysis was inconclusive as regards the backscattering of iron, as V-O-O multiple scattering dominated the WT modulus in the second shell (which "hid" the contribution from iron). However, the close similarity between the WT of the raw EXAFS spectrum and that of the model at least provides support of the correctness of our model approach (Fig. S1 and Fig. S2).

Table 3. Surface complexation reactions used in the CD-MUSIC model for ferrihydrite

\begin{tabular}{|c|c|c|c|c|}
\hline Reaction & $\Delta z_{0}, \Delta z_{1}, \Delta z_{2}{ }^{\mathrm{A}}$ & $\log K^{\mathrm{B}}$ & $95 \% \mathrm{CI}^{\mathrm{C}}$ & Source \\
\hline $\mathrm{FeOH}^{1 / 2-}+\mathrm{H}^{+} \leftrightarrow \mathrm{FeOH}_{2}^{1 / 2+}$ & $1,0,0$ & 8.1 & & [28] \\
\hline $\mathrm{Fe}_{3} \mathrm{O}^{1 / 2-}+\mathrm{H}^{+} \leftrightarrow \mathrm{Fe}_{3} \mathrm{OH}^{1 / 2+}$ & $1,0,0$ & 8.1 & & [28] \\
\hline $\mathrm{FeOH}^{1 / 2-}+\mathrm{Na}^{+} \leftrightarrow \mathrm{FeOHNa}^{1 / 2+}$ & $0,1,0$ & -0.6 & & [28] \\
\hline $\mathrm{Fe}_{3} \mathrm{O}^{1 / 2-}+\mathrm{Na}^{+} \leftrightarrow \mathrm{Fe}_{3} \mathrm{ONa}^{1 / 2+}$ & $0,1,0$ & -0.6 & & [28] \\
\hline $\mathrm{FeOH}^{1 / 2-}+\mathrm{H}^{+}+\mathrm{NO}_{3}^{-} \leftrightarrow \mathrm{FeOH}_{2} \mathrm{NO}_{3}^{1 / 2-}$ & $1,-1,0$ & 7.42 & & [28] \\
\hline $\mathrm{Fe}_{3} \mathrm{O}^{1 / 2-}+\mathrm{H}^{+}+\mathrm{NO}_{3}^{-} \leftrightarrow \mathrm{Fe}_{3} \mathrm{OHNO}_{3}^{1 / 2-}$ & $1,-1,0$ & 7.42 & & [28] \\
\hline $2 \mathrm{FeOH}^{1 / 2-}+2 \mathrm{H}^{+}+\mathrm{PO}_{4}^{3-} \leftrightarrow \mathrm{Fe}_{2} \mathrm{O}_{2} \mathrm{PO}_{2}^{2-}+2 \mathrm{H}_{2} \mathrm{O}$ & $0.46,-1.46,0$ & 27.59 & & [28] \\
\hline $2 \mathrm{FeOH}^{1 / 2-}+3 \mathrm{H}^{+}+\mathrm{PO}_{4}^{3-} \leftrightarrow \mathrm{Fe}_{2} \mathrm{O}_{2} \mathrm{POOH}^{-}+2 \mathrm{H}_{2} \mathrm{O}$ & $0.63,-0.63,0$ & 32.89 & & [28] \\
\hline $\mathrm{FeOH}^{1 / 2-}+3 \mathrm{H}^{+}+\mathrm{PO}_{4}^{3-} \leftrightarrow \mathrm{FeOPO}_{3} \mathrm{H}_{2}^{1 / 2-}+\mathrm{H}_{2} \mathrm{O}$ & $0.5,-0.5,0$ & 30.23 & & [28] \\
\hline $2 \mathrm{FeOH}^{1 / 2-}+\mathrm{H}^{+}+\mathrm{HVO}_{4}^{2-} \leftrightarrow(\mathrm{FeO})_{2} \mathrm{VO}_{2}^{2-}+2 \mathrm{H}_{2} \mathrm{O}$ & $0.4,-1.4,0$ & 16.39 & $16.32-16.46$ & This study \\
\hline $2 \mathrm{FeOH}^{1 / 2-}+2 \mathrm{H}^{+}+\mathrm{HVO}_{4}{ }^{2-} \leftrightarrow(\mathrm{FeO})_{2} \mathrm{VOOH}^{-}+2 \mathrm{H}_{2} \mathrm{O}$ & $0.65,-0.65,0$ & 23.20 & $23.07-23.34$ & This study \\
\hline $2 \mathrm{FeOH}^{1 / 2-}+3 \mathrm{H}^{+}+\mathrm{HVO}_{4}^{2-} \leftrightarrow(\mathrm{FeO})_{2} \mathrm{~V}(\mathrm{OH})_{2}+2 \mathrm{H}_{2} \mathrm{O}$ & $0.9,0.1,0$ & 27.44 & $26.36-28.51$ & This study \\
\hline
\end{tabular}

\section{Surface complexation model for vanadate(V)}

According to the EXAFS data, vanadate $(\mathrm{V})$ bound primarily as an edge-sharing bidentate vanadate $(\mathrm{V})$ complex on 2-line ferrihydrite. The XANES data provided further evidence for the tetrahedral nature of bound vanadate(V). In the modelling, the assumption that only singly coordinated $\equiv \mathrm{FeOH}$ groups were involved in the vanadate $(\mathrm{V})$ binding was applied. Surface site heterogeneity was not considered. Further, there were three bidentate complexes used in the optimized model, which represented different degrees of protonation of the bound vanadate(V) 
(Table 3). The model was able to provide a satisfactory fit to the vanadate(V) sorption data (Fig. 1, Fig. 3 and Table 3), with an R value of 0.963 as calculated by PEST. However, the model overestimated dissolved vanadate $(\mathrm{V})$ at the highest $\mathrm{Fe}: \mathrm{V}$ ratio. The $\equiv(\mathrm{FeO})_{2} \mathrm{VO}_{2}{ }^{2-}$ and the $\equiv(\mathrm{FeO})_{2} \mathrm{VOOH}^{-}$complexes dominate the speciation of vanadate across a wide $\mathrm{pH}$ range, whereas the third most protonated complex $\equiv(\mathrm{FeO})_{2} \mathrm{~V}(\mathrm{OH})_{2}$ was of some significance at low $\mathrm{pH}$, high surface coverage, and (in particular) in the presence of competing phosphate ions (Fig. 5).
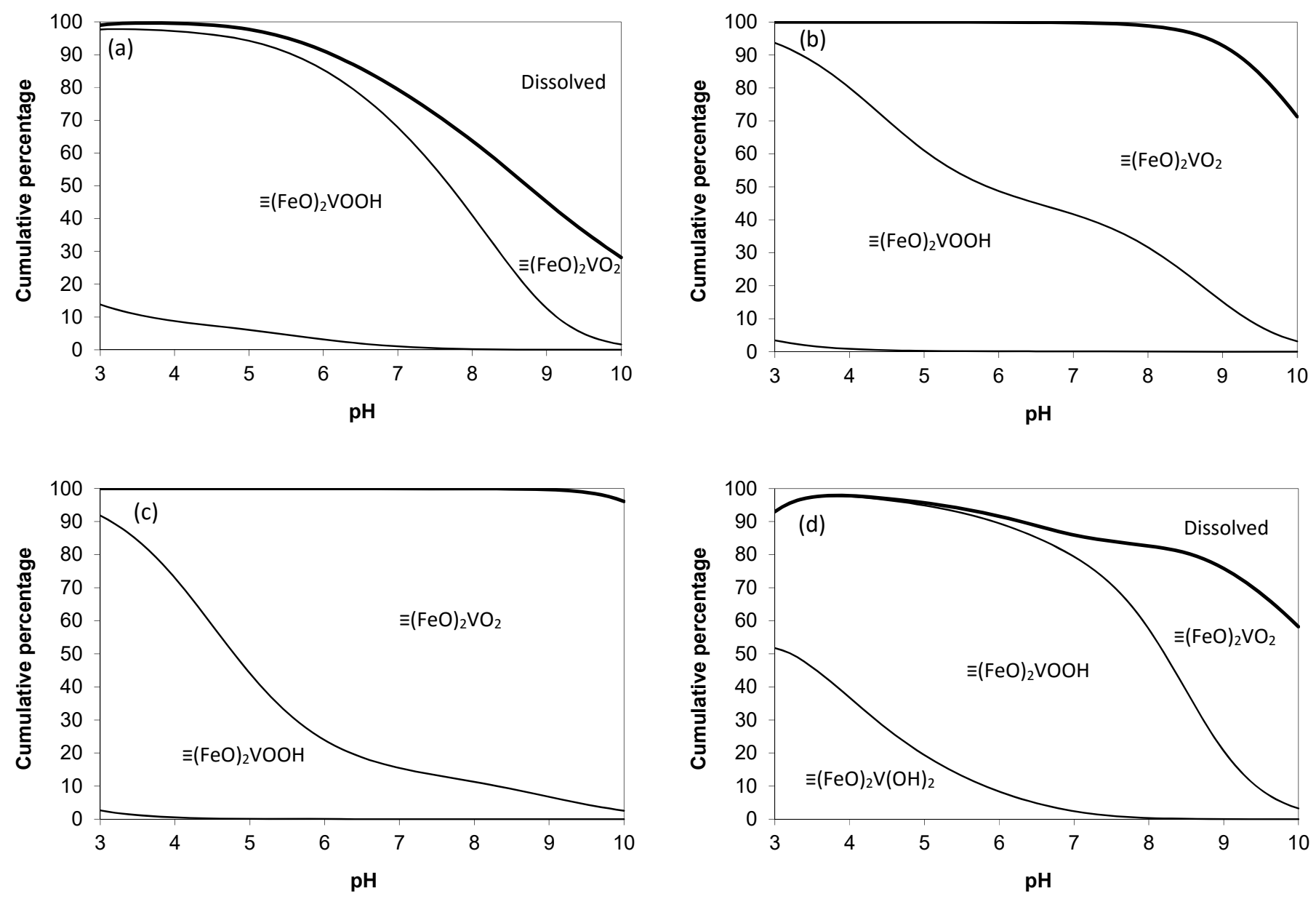

Fig. 5. Calculatated speciation of vanadate(V) as a function of $\mathrm{pH}$ in ferrihydrite systems. (a) $\mathrm{Fe}$ $=0.3 \mathrm{mM}, \mathrm{V}=50 \mu \mathrm{M}$; (b): Fe = $1 \mathrm{mM}, \mathrm{V}=50 \mu \mathrm{M}$; (c): Fe = $3 \mathrm{mM}, \mathrm{V}=50 \mu \mathrm{M}$; (d): Fe = $1 \mathrm{mM}$, $\mathrm{V}=50 \mu \mathrm{M}, \mathrm{P}=200 \mu \mathrm{M}$. 

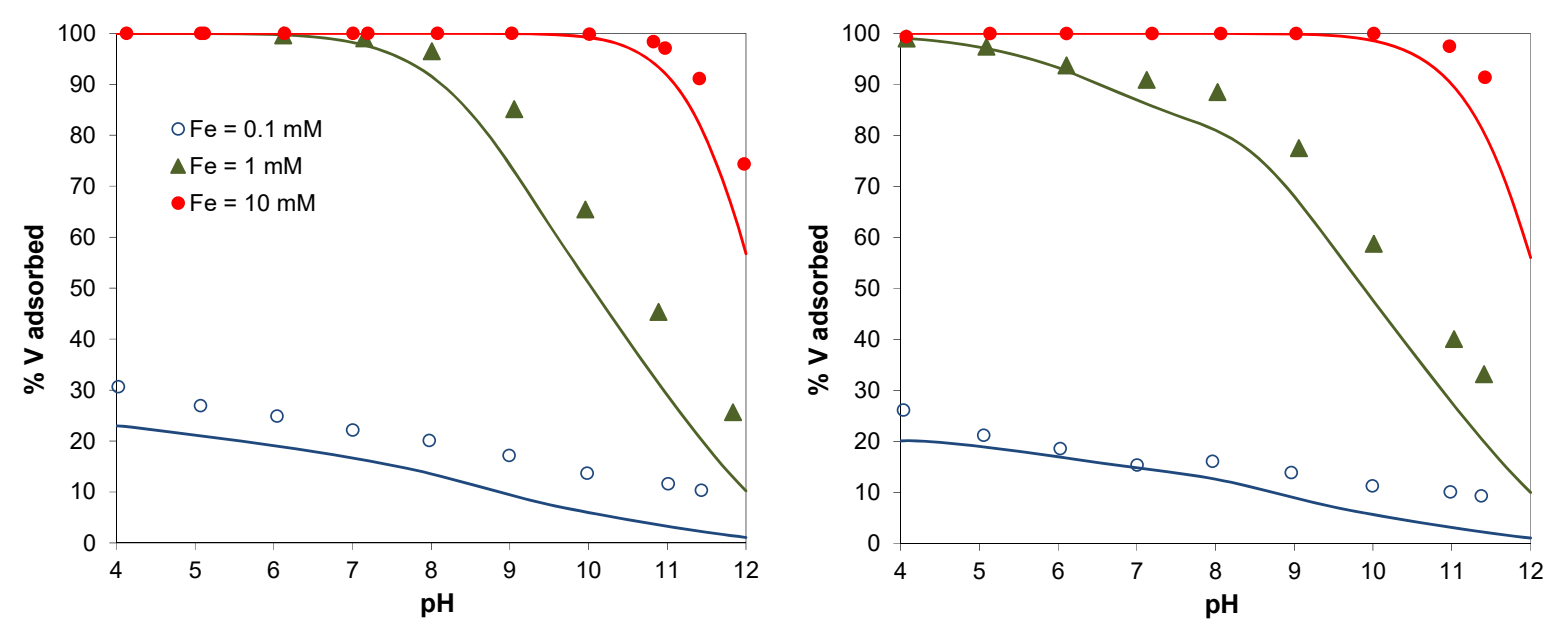

Fig. 6. Vanadate(V) sorption as a function of $\mathrm{pH}$ in the systems of Blackmore et al. ${ }^{[9]}$ Points are observations and lines are model predictions with the constants in Table 5. Left: Single-sorbate systems with total $\mathrm{V}=100 \mu \mathrm{mol} \mathrm{L}^{-1}$; right: ternary systems with total $\mathrm{V}=$ total $\mathrm{P}=100 \mu \mathrm{mol} \mathrm{L}$ ${ }^{1}$. The background electrolyte was $0.01 \mathrm{M} \mathrm{NaNO}_{3}$.

The model was able to describe the competitive interactions with phosphate well (Fig. 3), but the prediction of dissolved phosphate in the competitive system was somewhat less satisfactory. Further, the model systematically underpredicted vanadate $(\mathrm{V})$ adsorption to ferrihydrite for the data set published by Blackmore et al. ${ }^{[9]}$ although the model curves were of the same shape as the observations (Fig. 6).

\section{Discussion}

As for other anions, e.g. molybdate(VI) and phosphate, vanadate(V) adsorption to ferrihydrite decreases with increasing $\mathrm{pH} .{ }^{[14-15]}$ This adsorption pattern has been observed in other experiments performed with vanadate(V) on different iron (hydr)oxides. ${ }^{[5,7,11-12]}$ Also, vanadium redox reactions may be important to consider for correct interpretation of adsorption experiments. Under the conditions of our adsorption experiments, vanadyl(IV) was quantitatively oxidized to vanadate $(\mathrm{V})$. The $\mathrm{VO}^{2+}$ ion was probably oxidized by oxygen introduced from the solutions as no increase in iron content in solution was observed compared to experiments when vanadate(V) was 
added. It is known that the oxidation rate of $\mathrm{VO}^{2+}$ by oxygen increases in the occurrence of hydrolysis and adsorption to oxide surfaces. ${ }^{[2]}$ Addition of phosphate to the system decreased vanadate adsorption. Further, the vanadate adsorption edge changed its shape in the presence of phosphate. There was a clearly observable shoulder in the edge structure with a local minimum in vanadate(V) adsorption occurring at about $\mathrm{pH}$ 7.5. This shoulder could be fairly well reproduced by the CD-MUSIC model with the proposed parameters in which vanadate(V) and phosphate were assumed to bind as bidentate complexes (i.e., phosphate as a corner-sharing bidentate complex, whereas vanadate(V) was bound primarily as an edge-sharing bidentate complex). In general, the competitive interactions between phosphate and vanadate $(V)$ were significant, which means that competition from phosphate (and possibly from other oxyanions) is important to consider when predicting the adsorption of vanadate $(\mathrm{V})$ in environmental materials.

Vanadate(V) formed an edge-sharing bidentate complex on the ferrihydrite surface. The vanadate $(\mathrm{V})$ complex was however considerably different from the corner-sharing bidentate complexes that has been observed for vanadate $(\mathrm{V})$ on goethite. ${ }^{[11]}$ It was shown by Peacock and Sherman ${ }^{[1]}$ that vanadium(V) form a bidentate corner-sharing complex on goethite with two $\mathrm{V} \cdots$ Fe distances observed at $3.25 \AA$. The model included multiple V-O scattering paths and it was claimed that a simpler model would incorrectly indicate the presence of an edge-sharing complex. However, this was not found to be the case with our EXAFS spectra for which the inclusion of multiple V-O-O and V-O-Fe scattering paths did improve the model, yet this did not change the modelled V $\cdots$ Fe distances considerably. Furthermore, the WT analysis supported the model of an edge-sharing complex. The difference between the 2-line ferrihydrite and goethite concerning the vanadate(V) surface complex is probably due in part to the relatively large occurrence of singly coordinated groups on the iron(III) octahedra of ferrihydrite that are able to form bidentate edge $\left({ }^{1} \mathrm{E}\right)$ surface complexes. ${ }^{[39]}$ The results are consistent with the observations for molybdate, for which we observed a predominance of edge-sharing complexes on ferrihydrite ${ }^{[40]}$, whereas a mixture of edge- and corner-sharing complexes were observed on goethite. ${ }^{[41]}$ Also for copper(II) it has been reported that edge-sharing complexes are formed on ferrihydrite, ${ }^{[42]}$ whereas cornersharing complexes may be predominant on goethite. ${ }^{[43]}$ There may be a similar difference for uranium(VI), as a mixture of edge-sharing and corner-sharing complexes is observed on goethite, whereas edge-sharing complexes predominate on ferrihydrite. ${ }^{[44-45]}$ Further, arsenite is bound only as a corner-sharing bidentate complex on goethite, but partly also as an edge-sharing bidentate 
complex on ferrihydrite. ${ }^{[46]}$ Arsenate, however, is bound predominantly as corner-sharing complexes on both ferrihydrite and goethite. ${ }^{[16,47]}$ Possibly, the ion size of the different tetrahedral oxyanions may be one reason for the different behavior observed. Molybdate (Mo-O = 1.76 $\AA$ ) and vanadate $(\mathrm{V}-\mathrm{O}=1.72 \AA)$ are both larger than arsenate $($ As- $-\mathrm{O}=1.69 \AA)$, which possibly enables coordination as edge-sharing complexes.

In the surface complexation model, it was assumed that only singly coordinated $\equiv \mathrm{FeOH}$ groups were involved in vanadate binding. Equivalent model fits can also be obtained with a model in which the edge-sharing bidentate complexes involve one $\equiv \mathrm{FeOH}$ group and one doubly coordinated $\equiv \mathrm{Fe}_{2} \mathrm{OH}$ group, but such a model has other problematic issues. For example, the fitted $\mathrm{CD}$ values for the protonated surface complexes implied oversaturation of the surface oxygen ligands. Therefore, the use of the former model was preferred.

The fitted $\mathrm{CD}$ values for the $\equiv(\mathrm{FeO})_{2} \mathrm{VO}_{2}{ }^{2-}$ complex (Table 3) mean that 2.4 valence units (i.e. $48 \%$ of the total vanadium(V) valence) are transferred in the V-O surface bonds, i.e., clearly less than the 3 units needed to saturate the two surface oxygens in this type of complex. This was considered a realistic result since the surface oxygens normally are expected to be slightly undersaturated. ${ }^{[30]}$ This is true also for the protonated bidentate complexes (i.e. $\equiv(\mathrm{FeO})_{2} \mathrm{~V}(\mathrm{OH})_{2}$ and $\left.\equiv(\mathrm{FeO})_{2} \mathrm{VOOH}^{-}\right)$, in which the $\mathrm{CD}$ values imply that 2.9 and 2.65 valence units are transferred, respectively (i.e., $58 \%$ and $53 \%$ of the total vanadium(V) valence). The protonated complex $\equiv(\mathrm{FeO})_{2} \mathrm{~V}(\mathrm{OH})_{2}$, is notable because the bound vanadium is positively charged. Such a complex may be possible at $\mathrm{pH}<3.6$ in solution since the dioxovanadium(V) cation $\left(\mathrm{VO}_{2}{ }^{+}\right)$will predominate over $\mathrm{H}_{2} \mathrm{VO}_{4}{ }^{-}$and other vanadate species.

At very low surface coverages $(\mathrm{Fe}: \mathrm{V}=600)$, the model underestimated the vanadate $(\mathrm{V})$ sorption, at least at high $\mathrm{pH}$. At present no satisfactory explanation for this can be given. To improve the modelling at high $\mathrm{pH}$ a monodentate complex $\equiv \mathrm{FeOVO}_{3}{ }^{2.5-}$ can be added to the model. Although not directly supported by the EXAFS results, the presence of this complex would contribute with a weak second-shell contribution and would be difficult to distinguish if mixed with dominating bidentate complexes. Such a complex could improve the description of the single-sorbate systems at high Fe: $\mathrm{V}$ ratios. However, with a monodentate complex the model prediction of the ternary system deteriorated considerably (data not shown). It is therefore doubtful if the presence of a monodentate complex can explain the strong vanadate(V) sorption at high Fh:V ratios. A more likely explanation is the heterogeneous site-binding affinity, i.e. stronger vanadate(V) sorption to 
a small sub-fraction of surface groups. However, again the evidence for this is not sufficiently strong to merit explicit consideration in the model. Also, even if such high-affinity groups should exist, it is not clear if and to what extent they might be significant for vanadate(V) under field conditions, as these groups may also bind other solutes more strongly (such as silicic acid, phosphate and calcium).

Additional data sets would be needed to narrow the $95 \%$ confidence interval and hence increase the predictive power of the model. At present, there are few data reported in the literature concerning vanadate $(\mathrm{V})$ sorption to ferrihydrite. The most extensive data set, apart from our own, is the one of Blackmore et al. ${ }^{[7]}$ These authors used slightly different procedures during their experiment (e.g. ferrihydrite ageing time of only $1 \mathrm{~h}$ and equilibration time of only 30 minutes) compared to ours. Therefore their results may not be directly comparable to those in this study. Model predictions using the optimized parameters of Table 3 reveal that the model underestimated the V sorption in this system (Fig. 6). A possible reason for the stronger sorption in the system of Blackmore et al. ${ }^{[7]}$ may be the shorter ageing time of the ferrihydrite suspension before adding vanadate, which may have led to a larger accessible surface area. In any case this underlines the necessity to carry out additional experiments to bring down the uncertainty of the vanadate complexation constants.

\section{Conclusions}

Under oxic conditions, vanadate(V) adsorbed strongly to 2-line ferrihydrite and phosphate was a strong competitor for the sorption sites. By use of EXAFS spectroscopy, it was found that vanadate $(\mathrm{V})$ binds to 2-line ferrihydrite primarily as a edge-sharing bidentate complex with a $\mathrm{V} \cdots \mathrm{Fe}$ distance of about $2.8 \AA$ at $\mathrm{pH}$ 3.6-9.4. This complex is different from the corner-sharing complex that previously has been determined to be formed on goethite.

Vanadate(V) complexation to ferrihydrite could be described with the CD-MUSIC model using a combination of three bidentate complexes. To constrain the model sufficiently however, collection of additional data would be desirable. The results from this study are important for the understanding of vanadium chemistry in the environment and is a step in the direction to create a model that can describe vanadium adsorption in soils. 


\section{Supplementary material}

Recipes of batch experiments (Table S1), Results from vanadium K-edge XANES spectroscopy (Table S2), Morlet wavelet transforms of $k^{3}$-weighted vanadium K-edge EXAFS spectra of vanadium laboratory standards (Fig. S1) and experimental samples (Fig. S2).

\section{Acknowledgements}

This research was funded by the Swedish Steel AB Merox, Loussavaara-Kirunavaara Aktiebolag and Rautaruukki Corporation. Maxime Rasmus is acknowledged for carrying out parts of the laboratory work. Use of the Stanford Synchrotron Radiation Lightsource, SLAC National Accelerator Laboratory, is supported by the U.S. Department of Energy, Office of Science, Office of Basic Energy Sciences under Contract No. DE-AC02-76SF00515. The SSRL Structural Molecular Biology Program is supported by the DOE Office of Biological and Environmental Research, and by the National Institutes of Health, National Institute of General Medical Sciences (including P41GM103393). The contents of this publication are solely the responsibility of the authors and do not necessarily represent the official views of NIGMS or NIH. Portions of this research were carried out at beamline I811, MAX-Lab synchrotron radiation source, Lund University, Sweden. Funding for the beamline I811 project was kindly provided by The Swedish Research Council and The Knut och Alice Wallenbergs Stiftelse.

\section{References}

[1] R. B. Wanty, M. B. Goldhaber, Thermodynamics and kinetics of reactions involving vanadium in natural systems: Accumulation of vanadium in sedimentary rocks.

Geochim. Cosmochim. Acta 1992, 56, 1471.

[2] B. Wehrli, W. Stumm, Vanadyl in natural waters: Adsorption and hydrolysis promote oxygenation. Geochim. Cosmochim. Acta 1989, 53, 69.

[3] L.E. Seargeant, R.A. Stinson, Inhibition of human alkaline phosphatases by vanadate. Biochem. J. 1979, 181, 247.

[4] T. Wällstedt, L. Björkvald, J.P. Gustafsson, Increasing concentrations of arsenic and vanadium in (southern) Swedish streams. Appl. Geochem. 2010, 25, 1162.

[5] C.S. Shieh, I.W. Duedall, Role of amorphous ferric oxyhydroxide in removal of anthropogenic vanadium from seawater. Mar. Chem. 1988, 25, 121. 
[6] Y. Auger, L. Bodineau, S. Leclercq, M. Wartel, Some aspects of vanadium and chromium chemistry in the English Channel. Cont. Shelf Res. 1999, 19, 2003.

[7] D.P.T. Blackmore, J. Ellis, P.J. Riley, Treatment of a vanadium-containing effluent by adsorption/coprecipitation with iron oxyhydroxide. Water Res. 1996, 30, 2512.

[8] L. Brinza, L.G. Benning, P.J. Statham, Adsorption studies of Mo and V onto ferrihydrite. Miner. Mag. 2008, 72, 385.

[9] H.W. Martin, D.I. Kaplan, Temporal changes in cadmium, thallium, and vanadium mobility in soil and phytoavailability under field conditions. Water Air Soil Pollut. 1998, 101, 399.

[10] H.E. Gäbler, K. Gluh, A. Bahr, J. Utermann, Quantification of vanadium adsorption by German soils. J. Geochem. Explor. 2009, 103, 37.

[11] C.L. Peacock, D.M. Sherman, Vanadium(V) adsorption onto goethite (alpha-FeOOH) at pH 1.5 to 12: A surface complexation model based on ab initio molecular geometries and EXAFS spectroscopy. Geochim. Cosmochim. Acta 2004, 68, 1723.

[12] A. Naeem, P. Westerhoff, S. Mustafa, Vanadium removal by metal (hydr)oxide adsorbents. Water Res. 2007, 41, 1596.

[13] J.L. Jambor, J.E. Dutrizac, Occurrence and constitution of natural and synthetic ferrihydrite, a widespread iron oxyhydroxide. Chem. Rev. 1998, 98, 2549.

[14] J.P. Gustafsson, Modelling molybdate and tungstate adsorption to ferrihydrite. Chem. Geol. 2003, 200, 105.

[15] J. Antelo, S. Fiol, C. Perez, S. Marino, F. Arce, D. Gondar, R. Lopez, Analysis of phosphate adsorption onto ferrihydrite using the CD-MUSIC model. J. Colloid Interface Sci. 2010, 347, 112.

[16] D.M. Sherman, S.R. Randall, Surface complexation of arsenic(V) to iron(III) (hydr)oxides: Structural mechanism from ab initio molecular geometries and EXAFS spectroscopy. Geochim. Cosmochim. Acta 2003, 67, 4223.

[17] J.S. Loring, M.H. Sandström, K. Norén, P. Persson, Rethinking arsenate coordination at the surface of goethite. Chem. Eur. J. 2009, 15, 5063.

[18] T. Hiemstra, W.H. van Riemsdijk, A surface structural approach to ion adsorption: The charge distribution (CD) model. J. Colloid Interface Sci. 1996, 179, 488. 
[19] P.J. Swedlund, J.G. Webster, Adsorption and polymerisation of silicic acid on ferrihydrite, and its effect on arsenic adsorption. Water Res. 1999, 33, 3413.

[20] U. Schwertmann, R.M. Cornell, Iron oxides in the laboratory: preparation and characterization. 2000 (Wiley: New York).

[21] J.P. Gustafsson, I. Persson, D.B. Kleja, J.W.J. van Schaik, Binding of iron(III) to organic soils: EXAFS spectroscopy and chemical equilibrium modeling. Environ. Sci. Technol. 2007, 41, 1232.

[22] D.C. Crans, M. MahroofTahir, A.D. Keramidas, Vanadium chemistry and biochemistry of relevance for use of vanadium compounds as antidiabetic agents. Mol. Cell. Biochem. 1995, 153, 17.

[23] A. Thompson, D. Attwood, E. Gullikson, M. Howells, K.-J. Kim, J. Kirz, J. Kortright, I. Lindau, Y. Liu, P. Pianetta, A. Robinson, J. Scofield, J. Underwood, G. Williams, H. Winick, X-ray Data Booklet. 2009 (Lawrence Berkeley National Laboratory, University of California: Berkeley, CA).

[24] G.N. George, I.J. Pickering, EXAFSPAK - A Suite of Computer Programs for Analysis of X-ray Absorption Spectra. 1993 (SSRL: Stanford, CA)

[25] B. Ravel, M. Newville, ATHENA, ARTEMIS, HEPHAESTUS: data analysis for X-ray absorption spectroscopy using IFEFFIT. J. Synchrotron Rad. 2005, 12, 537.

[26] J. Wong, F.W. Lytle, R.P. Messmer, D.H. Maylotte, K-edge absorption spectra of selected vanadium compounds. Phys. Rev. B 1984, 30, 5596.

[27] A.L. Ankudinov, B. Ravel, J.J. Rehr, S.D. Conradson, Real-space multiple-scattering calculation and interpretation of X-ray-absorption near-edge structure. Phys. Rev. B 1998, 58, 7565.

[28] C. Tiberg, C. Sjöstedt, I. Persson, J.P. Gustafsson, Phosphate effects on copper(II) and lead(II) sorption to ferrihydrite. Geochim. Cosmochim. Acta 2013, 120, 140.

[29] T. Hiemstra, W.H. van Riemsdijk, A surface structural model for ferrihydrite I: Sites related to primary charge, molar mass, and mass density. Geochim. Cosmochim. Acta 2009, 73, 4423.

[30] T. Hiemstra, W.H. van Riemsdijk, A. Rossberg, K.U. Ulrich, A surface structural model for ferrihydrite II: Adsorption of uranyl and carbonate. Geochim. Cosmochim. Acta 2009, 73, 4437. 
[31] T. Hiemstra, W. Zhao, Reactivity of ferrihydrite and ferritin in relation to surface structure, size, and nanoparticle formation studied for phosphate and arsenate. ACS Nano 2016, in press. DOI: 10.1039/c6en00061d

[32] F.M. Michel, V. Barron, J. Torrent, M.P. Morales, C.J. Serna, J.F. Boily, Q.S. Liu, A. Ambrosini, A.C. Cismasu, G.E. Brown, Ordered ferrimagnetic form of ferrihydrite reveals links among structure, composition, and magnetism. P. Natl. Acad. Sci. USA 2010, 107, 2787.

[33] F.M. Michel, L. Ehm, S.M. Antao, P.L. Lee, P.J. Chupas, G. Liu, D.R. Strongin, M.A.A. Schoonen, B.L. Phillips, J.B. Parise, The structure of ferrihydrite, a nanocrystalline material. Science 2007, 316, 1726.

[34] T. Hiemstra, W.H. van Riemsdijk, On the relationship between charge distribution, surface hydration, and the structure of the interface of metal hydroxides. $J$. Colloid Interface Sci. 2006, 301, 1.

[35] J. Doherty, PEST, Model-independent parameter estimation, User Manual, $5^{\text {th }}$ ed. 2010. Watermark Numerical Computing.

[36] C. Tiberg, J.P. Gustafsson, Phosphate effects on cadmium(II) sorption to ferrihydrite. $J$. Colloid Interface Sci. 2016, 471, 103.

[37] D. Lundberg, A.S. Ullström, P. D'Angelo, I. Persson, A structural study of the hydrated and the dimethylsulfoxide, N,N '-dimethylpropyleneurea, and N,Ndimethylthioformaraide solvated iron(II) and iron(III) ions in solution and solid state. Inorg. Chim. Acta 2007, 360, 1809.

[38] H. Funke, A.C. Scheinost, M. Chukalina, Wavelet analysis of extended X-ray absorption fine structure data. Phys. Rev. B 2005, 71, 094110.

[39] T. Hiemstra, Surface and mineral structure of ferrihydrite. Geochim. Cosmochim. Acta 2013, 105, 316.

[40] J.P. Gustafsson, C. Tiberg, Molybdenum binding to soil constituents in acid soils: an XAS and modelling study. Chem. Geol. 2015, 417, 279.

[41] Y. Arai, X-ray spectroscopic investigation of molybdenum multinuclear sorption mechanism on the goethite-water interface. Environ. Sci. Technol. 2010, 44, 8491.

[42] A.C. Scheinost, S. Abend, K.I. Pandya, D.L. Sparks, Kinetic controls on $\mathrm{Cu}$ and $\mathrm{Pb}$ sorption by ferrihydrite. Environ. Sci. Technol. 2001, 35, 1090. 
[43] C.L. Peacock, D.M. Sherman, Copper(II) sorption onto goethite, hematite, and lepidocrocite: A surface complexation model based on ab initio molecular geometries and EXAFS spectroscopy. Geochim. Cosmochim. Acta 2004, 68, 2623.

[44] A. Singh, J.A. Catalano, K.U. Ulrich, D.E. Giammar, Molecular-scale structure of uranium(VI) immobilized with goethite and phosphate. Environ. Sci. Technol. 2012, 46, 6594.

[45] A. Rossberg, K.U. Ulrich, S. Weiss, S. Tsushima, T. Hiemstra, A. Scheinost, Identification of uranyl surface complexes on ferrihydrite: advanced EXAFS data analysis and CD-MUSIC modeling. Environ. Sci. Technol. 2009, 43, 1400.

[46] G. Ona-Nguema, G. Morin, F. Juillot, G. Calas, G.E. Brown, EXAFS analysis of arsenite adsorption onto two-line ferrihydrite, hematite, goethite, and lepidocrocite. Environ. Sci. Technol. 2005, 39, 9147.

[47] G.A. Waychunas, B.A. Rea, C.C. Fuller, J.A. Davis, Surface chemistry of ferrihydrite: Part 1. EXAFS studies of the geometry of coprecipitated and adsorbed arsenate.

Geochim. Cosmochim. Acta 1993, 57, 2251. 


\section{Supplementary material}

Vanadate complexation to ferrihydrite: X-ray absorption spectroscopy and CDMUSIC modelling

Maja A. Larsson, ${ }^{\mathrm{A}}$ Ingmar Persson, ${ }^{\mathrm{B}}$ Carin Sjöstedt ${ }^{\mathrm{A}}$ and Jon Petter Gustafsson ${ }^{\mathrm{A}, \mathrm{C}, \mathrm{D}}$

${ }^{\text {A}}$ Department of Soil and Environment, Swedish University of Agricultural Sciences, Box 7014, SE75007 Uppsala, Sweden.

${ }^{B}$ Department of Molecular Sciences, Swedish University of Agricultural Sciences, Box 7015, SE-750 07 Uppsala, Sweden.

${ }^{\mathrm{C}}$ Division of Land and Water Resources Engineering, Royal Institute of Technology, Teknikringen 76, SE-100 44, Stockholm, Sweden.

DCorresponding author. Email: jon-petter.gustafsson@slu.se 


\section{A. Batch experiments}

Table S1. Batch experiments performed with 2-line ferrihydrite and vanadate in a total of eight series ${ }^{A}$

\begin{tabular}{lccccccc}
\hline Series $^{\mathbf{B}}$ & $\begin{array}{c}\boldsymbol{n} \\
\text { samples }\end{array}$ & $\begin{array}{c}\mathbf{F e} \\
(\mathrm{mM})\end{array}$ & $\begin{array}{c}\mathbf{V} \\
(\mu \mathrm{M})\end{array}$ & $\begin{array}{c}\mathbf{P} \\
(\mu \mathrm{M})\end{array}$ & $\begin{array}{c}\text { Fe:V } \\
\text { ratio }\end{array}$ & $\begin{array}{c}\text { Fe:P } \\
\text { ratio }\end{array}$ & pH range \\
\hline L-1 & 11 & 0.3 & 50 & - & 6 & - & $3.21-9.53$ \\
$\mathrm{R}-1$ & 14 & 0.3 & 50 & - & 6 & - & $3.06-9.87$ \\
$\mathrm{~L}-2$ & 13 & 1 & 50 & - & 20 & - & $4.65-9.88$ \\
$\mathrm{R}-2$ & 17 & 1 & 50 & - & 20 & - & $3.02-10.10$ \\
L-3 & 14 & 3 & 50 & - & 60 & - & $5.31-10.30$ \\
$\mathrm{R}-3$ & 15 & 3 & 50 & - & 60 & - & $4.15-10.21$ \\
L-4 & 16 & 3 & 5 & - & 600 & - & $3.09-10.49$ \\
L-5 & 16 & 1 & 50 & 200 & 20 & 5 & $3.10-10.47$ \\
\hline
\end{tabular}

${ }^{\mathrm{A}} \mathrm{All}$ samples had an ionic strength of $0.01 \mathrm{M}$ added as $\mathrm{NaNO}_{3}$. Either $\mathrm{HNO}_{3}$ or $\mathrm{NaOH}$ was added to adjust the $\mathrm{pH}$ value.

${ }^{\mathrm{B}}$ The R series were processed by M. Rasmus at KTH Royal Institute of Technology (KTH) in May 2009. The L series were prepared by M. A. Larsson at the Swedish University of Agricultural Sciences (SLU) in September 2009.

B. Results from vanadium K-edge XANES spectroscopy

Table S2. Pre-edge properties and K-edge positions of standards and ferrihydrite samples

\begin{tabular}{|c|c|c|c|c|}
\hline \multirow[t]{2}{*}{ Sample } & \multicolumn{3}{|c|}{ Pre-edge peak } & \multirow{2}{*}{$\begin{array}{l}\text { Main edge } \\
E_{1 / 2}(e V)^{\mathrm{A}}\end{array}$} \\
\hline & Area & Intensity & Centroid position (eV) & \\
\hline \multicolumn{5}{|l|}{ Standards } \\
\hline $\mathrm{V}_{2} \mathrm{O}_{5}(\mathrm{~s})$ & 1.9 & 0.66 & 5469.4 & 5480.6 \\
\hline $\mathrm{VO}^{2+}(\mathrm{aq})$ & 1.0 & 0.36 & 5469.9 & 5478.8 \\
\hline $\mathrm{H}_{2} \mathrm{VO}_{4}^{-}(\mathrm{aq})$ & 2.2 & 0.81 & 5469.8 & 5481.0 \\
\hline \multicolumn{5}{|l|}{ Ferrihydrite } \\
\hline $\mathrm{C}$ & 1.9 & 0.78 & 5469.9 & 5482.0 \\
\hline $\mathrm{D}$ & 1.9 & 0.80 & 5469.6 & 5481.7 \\
\hline $\mathrm{F}$ & 1.9 & 0.84 & 5469.7 & 5481.7 \\
\hline
\end{tabular}

${ }^{A} E_{1 / 2}=$ the energy on the main edge where the normalized intensity $=0.5$. 


\section{Wavelet transform analysis}

Calculation of Morlet wavelet transforms was made as described by Tiberg et al. ${ }^{[1]}$
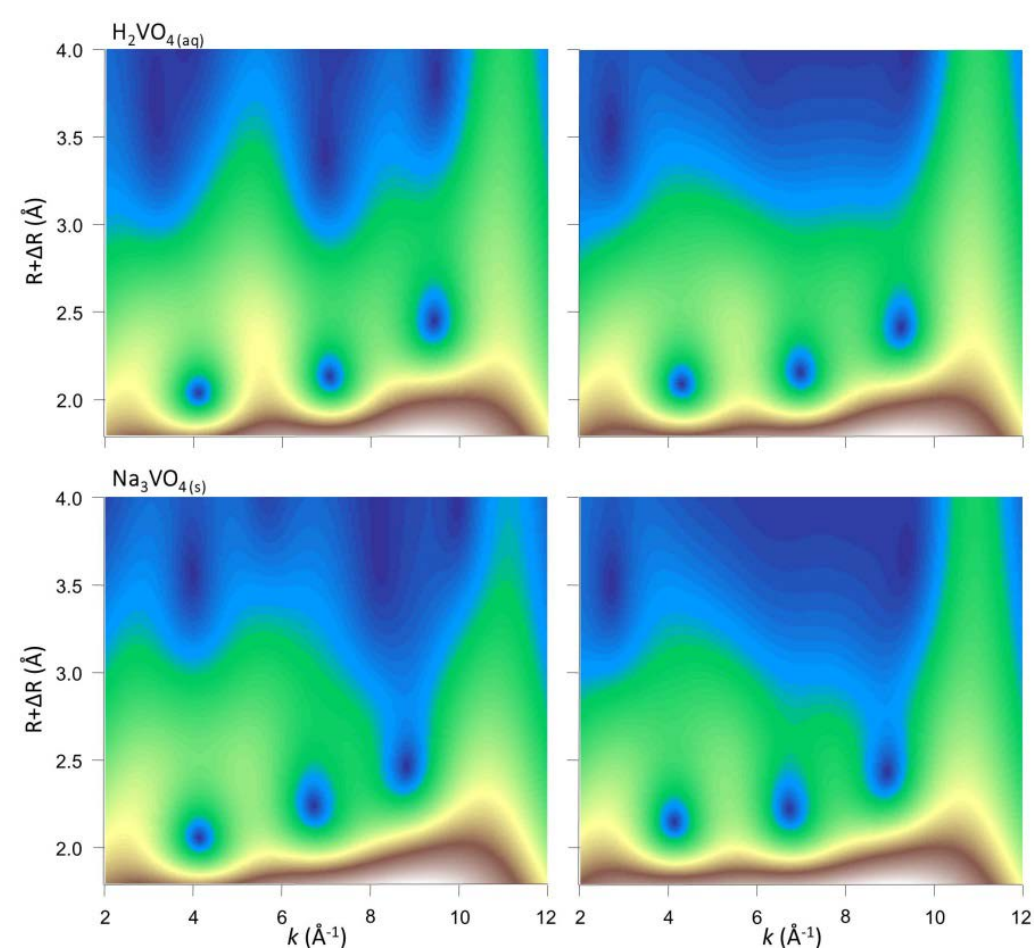

Fig. S1. Morlet wavelet transforms of $k^{3}$-weighted vanadium K-edge EXAFS spectra of vanadium laboratory standards, solid and dissolved vanadate samples ( $\kappa=6, \sigma=1)$. Experimental data (left) and modelled data (right). 

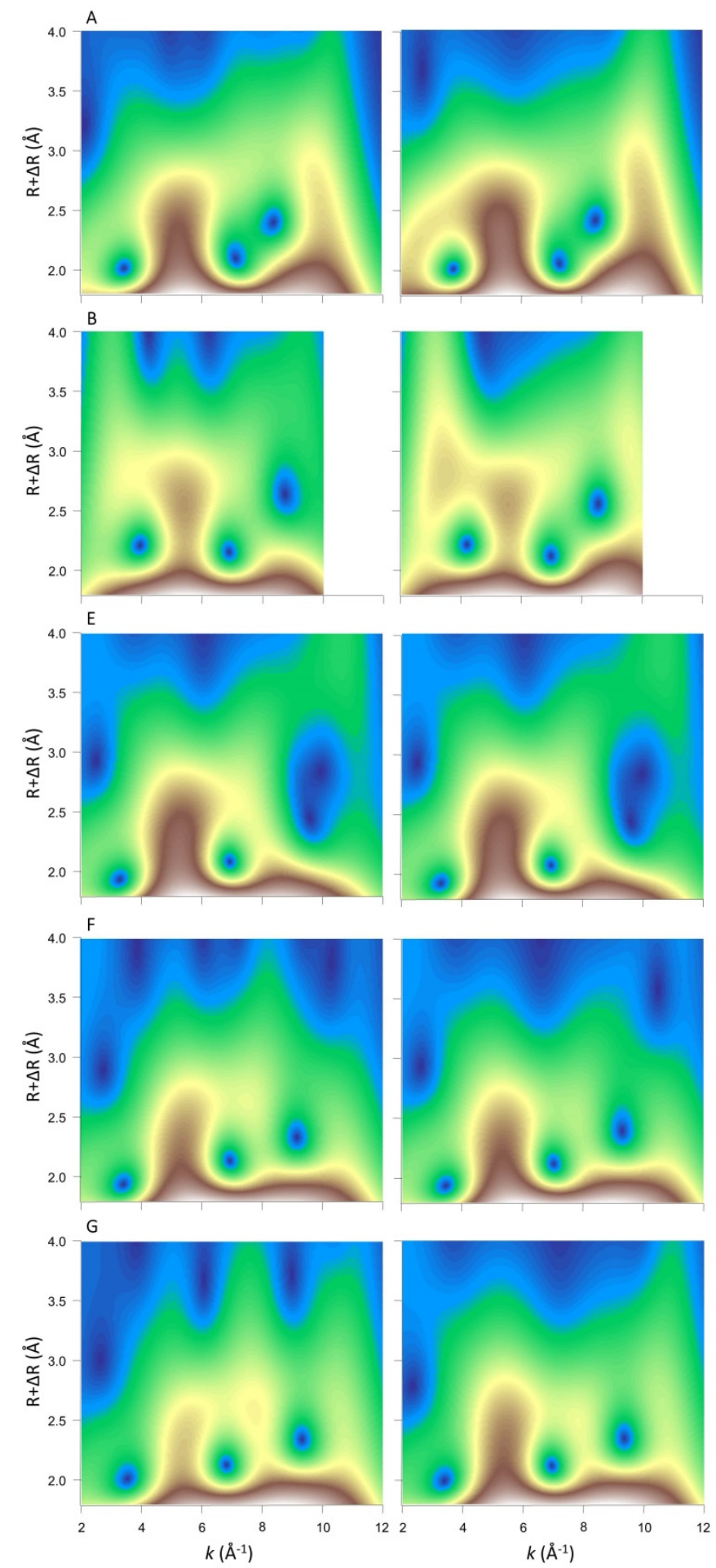

Fig. S2. Morlet wavelet transforms of $k^{3}$-weighted vanadium K-edge EXAFS spectra of samples A, B, E, F and $\mathrm{G}(\kappa=6, \sigma=1)$. Experimental data (left) and modelled data (right).

\section{References}

[1] C. Tiberg, C. Sjöstedt, I. Persson, J.P. Gustafsson, Phosphate effects on copper(II) and lead(II) sorption to ferrihydrite. Geochim. Cosmochim. Acta 2013, 120, 140. 